\title{
Caracterização gravimétrica e projeção de geração dos resíduos sólidos no município de Curaçá/BA
}

Os aumentos exacerbados dos resíduos sólidos nos municípios têm gerado grandes impactos sociais e ambientais, caminhando em contramão à legislação vigente instituída pela Política Nacional dos Resíduos Sólidos. É a partir dessa perspectiva que o presente trabalho se dedica a diagnosticar o manejo dos resíduos sólidos da sede do munícipio de Curaçá/BA, visando realizar a identificação de aspectos relacionados à composição, coleta e a disposição final. Para tal, avaliou-se a gestão, a infraestrutura de destinação final dos resíduos e realizou-se a caracterização, a partir da análise gravimétrica, dos mesmos. A cidade dispõe de um 'lixão' para fazer o descarte dos resíduos gerados, constatando a infraestrutura insipiente. Além disso, $60 \%$ dos resíduos produzidos na sede são oriundos da matéria orgânica. Portanto, soluções como a compostagem e a produção de biogás tornam-se processos que minimizam os impactos ambientais e são atividades que podem ser conduzidas de maneira sustentável.

Palavras-chave: Resíduos sólidos; Infraestrutura; Gestão; Caracterização gravimétrica.

\section{Gravimetric characterization and projection of solid waste generation in the municipality of Curaçá/BA}

\begin{abstract}
The exacerbated increase of solid waste in the municipalities has generated great social and environmental impacts, moving against the current legislation instituted by the National Solid Waste Policy. It is from this perspective that the present work is dedicated to diagnose the solid waste management of the city hal of Curaçá/BA, in order to identify aspects related to composition, collection and final disposal. For this, the management, the infrastructure for the final destination of the waste was evaluated and the characterization, from the gravimetric analysis, of the same was carried out. The city has a 'dump' to dispose of the generated waste, noting the insipid infrastructure. In addition, $60 \%$ of the waste produced at headquarters is derived from organic matter. Therefore, solutions such as composting and biogas production become processes that minimize environmental impacts and are activities that can be conducted in a sustainable way.
\end{abstract}

Keywords: Solid Waste; Infrastructure; Management; Gravimetric characterization.

Topic: Engenharia Ambiental

Reviewed anonymously in the process of blind peer.
Received: 14/01/2018

Approved: $25 / 04 / 2018$
Heitor de Santana Rodrigues

Universidade Federal do Vale do São Francisco, Brasil

http://lattes.cnpq.br/2995614292260689

rotieh94@hotmail.com

\section{Emanuela Gonçalves}

Universidade Federal do Vale do São Francisco, Brasil

http://lattes.cnpq.br/7569183784477163

emanuela.goncalves@outlook.com

Iara Jeanice Souza Ferreira

Universidade Federal do Vale do São Francisco, Brasil

http://lattes.cnpq.br/9194131634003509

iarajeanice@hotmail.com
Miriam Cleide Cavalcante Amorim

Universidade Federal do Vale do São Francisco, Brasil

http://lattes.cnpq.br/8379984717099508

miriamcleidea@gmail.com
Referencing this:

RODRIGUES, H. S.; GONÇALVES, E.; FERREIRA, I. J. S.; AMORIM, M. C. C.. Caracterização gravimétrica e projeção de geração dos resíduos sólidos no município de Curaçá/BA. Natural Resources, v.8, n.1, p.4151, 2018. DOI: http://doi.org/10.6008/CBPC2237-9290.2018.001.0005 


\section{INTRODUÇÃO}

Em meados dos anos 70 as políticas de controle de resíduos sólidos buscavam estabelecer normas referentes ao gerenciamento dos resíduos sólidos, mas somente nos anos 80 estabeleceu formas de prétratamento e destruição do material. A tendência nos países, atualmente, é o aumento dos resíduos sólidos, provenientes de indústrias e da sociedade consumista que se acostumou ao descartável.

Segundo dados do Sistema Nacional de Informações Sobre Saneamento (SNIS, 2017), oriundos da 14a publicação do Diagnóstico do Manejo de Resíduos Sólidos Urbanos, a massa coletada de resíduos domiciliares e públicos resultaram em um montante de 62,5 milhões de toneladas por ano ou 171,3 mil toneladas por dia. Sendo que apurou-se que $60,9 \%$ são dispostas em aterros sanitários, $11,5 \%$ em aterros controlados, 2,3\% encaminhados para unidades de triagem e compostagem, restando então uma parcela de 15,4\% sem informação, a qual se refere sobretudo aos pequenos municípios de até 30 mil habitantes. Além do mais, 10,1\% dos municípios ainda dispõem seus resíduos de forma inadequada em lixões.

A Política Nacional dos Resíduos Sólidos (PNRS), Lei Federal de № 12.305 promulgada em 2010, entra com a missão de alterar o cenário atual encontrado nos municípios brasileiros solucionando os problemas ambientais, sociais e econômicos derivados da disposição inadequada dos resíduos sólidos. Para tanto faz-se necessário elaborar Plano Municipal de Gestão Integrada de Resíduos Sólidos (PMGIRS) como condição necessária para os municípios terem acesso aos recursos da União, destinada à limpeza urbana e ao manejo de resíduos sólidos. O referido Plano também deverá ter em seu conteúdo o diagnóstico da situação quanto à geração no respectivo território, indicando a origem, o volume, a caracterização e as formas de destinação e disposição final.

A necessidade de um estudo que venha caracterizar e analisar os resíduos sólidos torna-se cada vez mais importante, para que a partir desses dados como, por exemplo, a qualidade dos materiais e o volume possa subsidiar programas que venham minimizar os impactos gerados e melhorar o gerenciamento dos mesmos. Cada sociedade gera um determinado tipo de resíduo sólido, uma mistura de materiais que varia em função de hábitos e costumes da população, do clima e da estação, e das atividades econômicas existentes no município e que mudam ao longo do tempo. Os autores acrescentam que é indispensável à identificação periódica das características dos resíduos sólidos gerados pelo município, que é o estudo primordial para se caracterizar tanto sua quantidade quanto sua tipologia. O sucesso de qualquer programa de gerenciamento de resíduos é fundamental, portanto, conhecer detalhadamente o que se gera para planejar todo o sistema de gestão.

Dentre os munícipios brasileiros que ainda precisam adotar as medidas estabelecidas pela PNRS, Curaçá, localizado na Bahia, é um município que possui uma população de 32.165 habitantes, sendo 13.720 residentes na zona urbana e 18.445 na zona rural e no que diz respeito aos RSU, 43,97\% são coletados por serviços de limpeza, $38,54 \%$ são queimados na propriedade, $0,7 \%$ enterrado na propriedade e $16,78 \%$ outro destino. Cabe destacar que o município faz parte da região integrada de desenvolvimento econômico (RIDE), 
ou seja, os recursos públicos destinados às RIDE's visam promover o desenvolvimento através de investimentos em áreas que amenizem as desigualdades sociais, como o saneamento básico.

Portanto, a fim de proceder o estudo dos resíduos sólidos, o presente trabalho objetivou avaliar as condições de infraestrutura através de um checklist, as condições de manejo dos resíduos sólidos, através de aplicação de questionários para a gestão local e identificar a composição gravimétrica dos RSD na sede do município de Curaçá/BA visando estimar o quantitativo de resíduos sólidos domésticos (RSD) gerado e a descrição dos bairros e a correlação com a composição gravimétrica dos RSD.

\section{METODOLOGIA}

A área de abrangência do estudo envolve a sede de Curaçá/BA, que está situado à margem direita do rio São Francisco, distante 553 km da capital baiana, estando a uma altitude de 366 metros, localizada na Latitude $8^{\circ} 59^{\prime} 31^{\prime \prime}$ sul e uma Longitude $39^{\circ} 54^{\prime} 28^{\prime \prime}$ oeste com uma área de 6.079,022 km² (IBGE, 2001). A sede da cidade é constituída de oito bairros, são eles: Centro (C), Centro Histórico (C.H.), Alto da Loira (A.L.), Loteamento Salvador (L.S.), Casas Populares (C.P.), Vila da Paz (V.P.), Bambuí (B) e José Amâncio Filho (J.A.F).

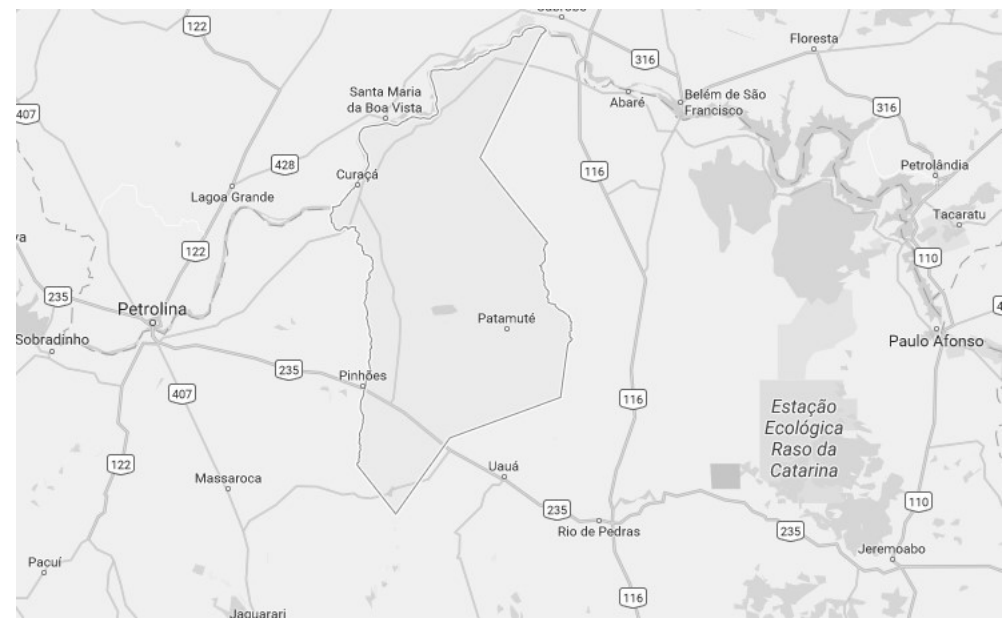

Figura 1: Foto de Município de Curaçá.

\section{Infraestrutura da sede de Curaçá para os RSDS}

Aplicou-se um checklist, através de visita exploratória nas ruas da sede de Curaçá/BA, desenvolvido para certificar as instalações de infraestrutura local, com orientação de um membro do Departamento do Meio Ambiente da prefeitura municipal de Curaçá e registros fotográficos do espaço. O checklist foi elaborado de modo a compreender as ferramentas que a cidade apresenta quanto ao que determina o Plano Nacional de Saneamento Básico, referentes à distribuição de lixeiras, presença de coleta seletiva, varrição e limpeza de logradouros e vias.

\section{Gestão local dos resíduos sólidos}

Foi elaborado um questionário destinado aos gestores do setor de meio ambiente da Prefeitura Municipal de Curaçá/BA no intuito de verificar as competências atribuídas aos Órgãos competentes às áreas de abrangência e seus serviços direcionados a resíduos sólidos e limpeza urbana. O questionário apresentou 
perguntas sobre a coleta e frequência nos mais diferentes ambientes de resíduos domiciliares, construção civil, podas de árvores, serviços de saúde, feiras livres, capinação de vias públicas, resíduo agroindustrial e destinação final.

\section{Gravimetria dos RSD}

O estudo atendeu um período da coleta das amostras foi mensal e ocorreu nos meses de março, abril e maio de 2015, entre terça-feira a quinta-feira, fora de época de festividades e férias escolares. Através da Equação 1 obteve-se uma amostra total de 24 residências divididas em três residências por bairro, comtemplando 8 bairros da sede Curaçá. Para atender aos critérios de precisão e de correção dos procedimentos amostrais, adotou-se um percentual de $95 \%$ de confiabilidade com uma margem de erro estipulada em $5 \%$, e a seguinte fórmula foi utilizada para a realização do cálculo amostral:

$$
\mathrm{n}=\frac{\mathrm{Z}^{2} \times \mathrm{p} \times \mathrm{q} \times \mathrm{N}}{\mathrm{d}^{2}(\mathrm{~N}-1)+\mathrm{Z}^{2} \times \mathrm{p} \times \mathrm{q}}
$$

$$
\begin{array}{r}
\text { Onde: } \\
\mathrm{n}=\text { tamanho da amostra; } \\
\mathrm{N}=\text { tamanho da população }=500 \text { domicílios; } \\
\mathrm{p}=\text { estimativa da proporção }=0,5 ; \\
\mathrm{q}=1-\mathrm{p}=0,5 ; \\
\mathrm{Z}=\text { nível de confiança estabelecido }=95 \%=1,96 ; \\
\mathrm{d}=\text { erro amostral }=5 \%=0,05
\end{array}
$$

No levantamento da gravimetria dos RSD, os componentes foram diferenciados nas seguintes categorias: matéria orgânica, papel/papelão, plástico, vidro, material eletrônico, metal, rejeito e outros materiais. Os procedimentos adotados no levantamento gravimétrico dos RSD foram: entrega de duas sacolas nas residências com capacidade de 30 litros nas residências e após $24 \mathrm{~h}$ a coleta dos RSD realizada por numa van, os resíduos foram transportados para Universidade Federal do Vale do São Francisco, para a realização do estudo gravimétrico, em seguida, as sacolas foram acondicionadas em uma lona plástica; as sacolas já nas lonas foram rompidas e foi realizado a separação dos resíduos de acordo com as categorias citadas acima; em seguida foram pesados em uma balança digital Modelo Mark 6500 com capacidade até 6,5kg; após a coleta dos dados, as informações foram digitadas em planilha do programa Excel disposto no pacote da Microsoft Office.

\section{Projeção estimada da geração dos resíduos}

Para estimar a projeção dos resíduos sólidos domésticos para os próximos vinte anos, utilizaram-se a Equação 2 e 3, elaboradas a partir de dados retirados do Datasus, sendo que as informações quanto ao crescimento populacional do município foram obtidas pelo IBGE, um valor correspondente a 1,6\% determinado assim como a estimativa de geração de resíduos por habitantes.

$$
\begin{aligned}
& \mathrm{tx}=\frac{\mathrm{Q}}{\mathrm{P}} \quad \text { (Equação 2) } \\
& \mathrm{Qf}=\mathrm{Pf} \times \mathrm{tx} \quad(\text { Equação 3) }
\end{aligned}
$$




\section{RESULTADOS E DISCUSSÕES}

\section{Infraestrutura dos RSU}

O checklist realizado demonstrou as condições de infraestrutura local referente aos resíduos sólidos e os serviços de limpeza, onde $92 \%$ das ruas analisadas não apresentaram lixeiras distribuídas, faltando em todos papas entulhos destinados para coleta de construção civil. Apenas $36 \%$ havia manutenção das vias públicas. Também se constatou que, em se tratando de carros de lixo circulando para coleta dos resíduos sólidos urbanos, $79 \%$ das ruas são contempladas. Existe coleta seletiva em apenas $1 \%$ das ruas até 0 momento, todavia o mesmo encontra-se em fase de implantação integrado com sede municipal e estadual em parceria com a Mineração Caraíba. Das ruas visitadas nenhuma apresentou instalação de Cooperativas destinada à reciclagem, embora o município detenha de Cooperativa (Tabela 1).

Tabela 1: Percentual dos dados obtidos no Município de Curaçá - BA sobre as condições de Resíduos Sólidos em Infraestrutura.

\begin{tabular}{|c|c|c|c|}
\hline Questão & Perguntas & Respostas & Porcentagem (\%) \\
\hline 1 & Lixeiras Distribuídas & Sim/Não & $8 / 92$ \\
\hline 2 & Papa entulhos instalados & Sim/Não & $0 / 100$ \\
\hline 3 & Manutenção nas vias públicas & Sim/Não & $36 / 64$ \\
\hline 4 & Carros de lixo circulando nas ruas & Sim/Não & $79 / 21$ \\
\hline 5 & Coletores seletivos distribuídos & Sim/Não & $0 / 100$ \\
\hline 6 & Serviço de coleta seletiva na rua & Sim/Não & $1 / 99$ \\
\hline 7 & Cooperativa de reciclagem na rua & Sim/Não & $0 / 100$ \\
\hline 8 & Reforma ou construção de infraestrutura & Sim/Não & $0 / 100$ \\
\hline
\end{tabular}

Além disto, através da visita in loco, pôde-se constatar que o município apresenta lixão como fonte de destinação final dos resíduos sólidos com exceção dos resíduos de serviços de saúde, os demais são destinados ao lixão municipal. O lixão de Curaçá trata-se de um espaço destinado a disposição dos resíduos a céu aberto, sem tratamento prévio contendo o contato direto com o solo, sem controle ambiental. Assim, o chorume que é produzido a partir da decomposição da matéria orgânica penetra no solo, podendo causar contaminação aos lençóis freáticos. É notável a presença de roedores e vetores no local assim como outros tipos de animais, além de pessoas trabalhando de forma inadequada, entretanto este trabalho oferece a reciclagem dos materiais e, como consequência geração de renda para estas pessoas.

Segundo Jacobi (2006), os resíduos sólidos possuem várias denominações, naturezas, origens diferenciadas e diversas composições. A gestão dos vários tipos de resíduos tem responsabilidades definidas em legislações específicas, implicando em sistemas diferenciados de coleta, tratamento e disposição final. Desta forma, demonstra-se que o lixão é um mecanismo obsoleto, além de ser considerado um dos piores 
métodos de destinação final dos resíduos gerados do ponto de vista ambiental, como pode ser ilustrado na Figura 2.
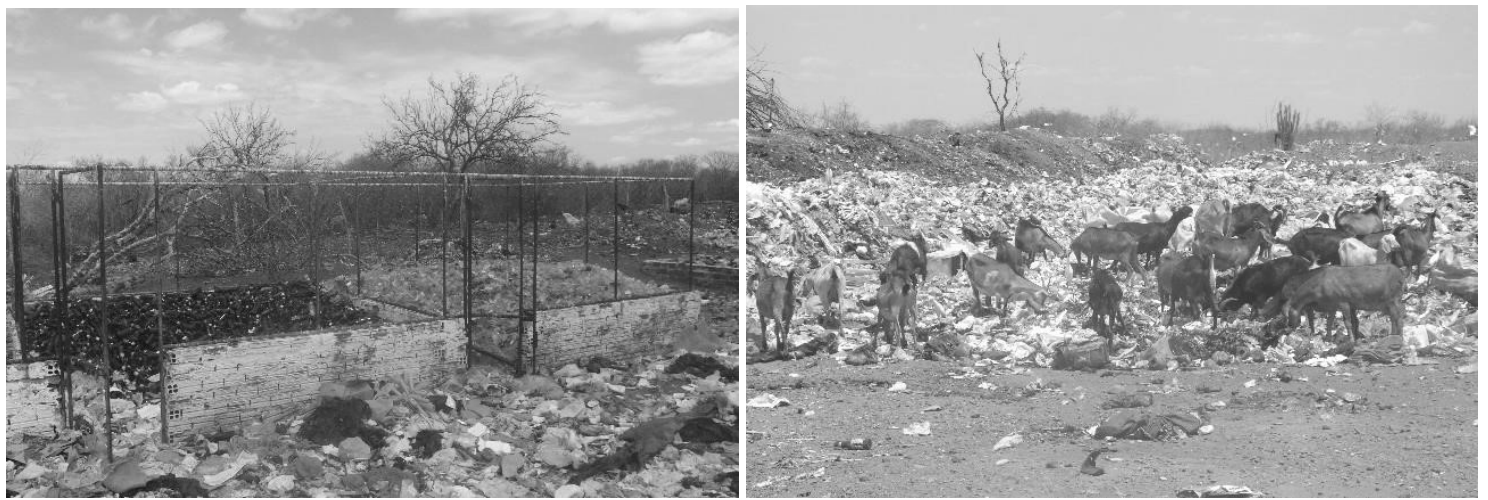

Figura 2: Destinação dos resíduos sólidos domiciliares do Município de Curaçá.

Neste contexto, a Política Nacional dos Resíduos sólidos, traz um conjunto muito abrangente de diretrizes, que cobrem todos os aspectos necessários transformação desse cenário, indo para origem do problema, criando diversas medidas que resultarão no maior aproveitamento dos resíduos e na redução dos rejeitos. É evidente a necessidade de ampliação e diversificação acelerada da infraestrutura de destinação no município, para isto serão necessários grandes investimentos na infraestrutura, estes podem ser públicoprivadas, que entra nesse cenário como uma alternativa segura, onde possibilita ao poder público direcionar para áreas de maior carência.

\section{Gestão Local dos RSUs}

Com base no questionário aplicado, podem-se obter as seguintes informações: Os serviços de limpeza urbana são realizados na sede e nos distritos de Curaçá, sendo de competência da Secretaria de Infraestrutura. É de responsabilidade da Secretaria, a capinação de vias públicas, a poda de arvores, segundo as informações prestadas pelo Órgão, possui frequência diária. A coleta, frequência e destinação final dos resíduos domiciliares; agroindustrial; de construção civil; podas de árvores; limpeza nas praças; limpeza em feira livre é de cargo de empresas terceirizadas que desenvolve este serviço contendo uma frequência apresentada na Tabela 2.

Segundo o gestor da secretaria de Infraestrutura, na sede consta com a presença de uma associação de catadores, porem a secretaria não faz parceria com a mesma, sendo regida apenas pelos catadores locais. A gestão integrada e sustentável dos resíduos sólidos inclui a redução da produção nas fontes geradoras, o reaproveitamento, a coleta seletiva com inclusão de catadores de materiais recicláveis e a reciclagem, e ainda a recuperação de energia (KLUNDERT, 2001; ADEDIPE, 2005).

Tabela 2: Representação dos tipos de resíduos, frequência de coleta e destinação final.

\begin{tabular}{lll}
\hline Resíduos Coletados & Frequência da coleta & Destinação final \\
\hline Domiciliar & 3 vezes por semana & Lixão \\
Agroindustrial & 1 vez por semana & Incineração \\
Hospitalar & 1 vez por semana & Incineração \\
Limpeza urbana & Todos os dias & Lixão \\
Construção civil & 1 vez por semana & Lixão \\
\hline
\end{tabular}


O município de Curaçá/BA é regido pelo Código de Meio Ambiente de № 547/2010, de 02 de junho de 2010 e pela Agenda 21 que abrange o município e seus respectivos distritos. O distrito não contempla nenhum programa de educação ambiental e não existe taxa cobrada para os serviços de resíduos sólidos e limpeza urbana. No momento, ainda não há perspectiva para realizar o Plano Municipal de Gestão Integrada de Resíduos Sólidos tal como implica a Política Nacional de Resíduos Sólidos. Desse modo, percebe-se uma divergência, visto que há a existência de lei municipal que está em consonância com as questões ambientais e com a Lei Federal, porém a realidade demonstra que ainda não se aplica na sede do município. Dessa forma, constata-se que a gestão necessita de revisão quanto às ações aplicadas no desenvolvimento ambiental.

Segundo o gestor, Curaçá consta com um projeto de aterro sanitário que foi embargado no meio da operação de instalação, assim o município ainda consta com o lixão para a destinação final dos resíduos sólidos. De acordo com o diagnóstico realizado pelo SINIR, 42\% dos municípios nordestinos utilizam de "lixão" como destinação final.

\section{Análise Gravimétrica}

A gravimetria revela o quantitativo dos resíduos de cada constituinte em relação ao peso total da amostra. Para a sede de Curaçá, os resultados obtidos pela caracterização dos resíduos sólidos estão baseados em teores de matéria orgânica, plásticos, metais, vidros, papel, material eletrônico, entre outros. A caracterização dos resíduos sólidos foi realizada afim de identificar a potencialidade econômica na sede do município de Curaçá, Tabela 3, obtendo um maior teor de matéria orgânica e segundo lugar para rejeito (material não reutilizável). De acordo com Monteiro et al. (2001) as principais características físicas estão baseadas na geração per capita, que relaciona a quantidade de resíduos urbanos gerada diariamente e o número de habitantes de determinada região e a composição gravimétrica que representa o percentual de cada componente em relação ao peso total da amostra de lixo analisada. Ademais, em países como Brasil, Alemanha, Holanda e Estados Unidos, a composição gravimétrica dos resíduos sólidos é basicamente matéria orgânica, vidro, metal, plástico e papel (MONTEIRO et al., 2001).

No município de Curaçá, na composição dos RSDs, matéria orgânica apresentou 63\% (Figura 3) na composição, o que está coerente com a porcentagem média do material orgânico de origem domestica encontrado por Cempre, que é cerca de 60\%. Segundo Ministério do Meio Ambiente (MMA) os resíduos orgânicos provenientes de atividades agrossilvopastoris e industriais, os dados do Plano Nacional de Resíduos Sólidos indicam que há uma geração anual de 800 milhões de toneladas de resíduos orgânico, e correspondem a mais de $50 \%$ do total de RSU gerados no Brasil.

Tabela 3: Geração per capita de resíduos sólidos de Curaçá.

\begin{tabular}{l|l|l|l|l|l|l|l}
\hline Resíduos & Plástico & Papel & Metal & Vidro & M. O. & Eletrônico & Rejeito \\
\hline $\begin{array}{l}\text { Total } \\
\text { (g/hab/dia) }\end{array}$ & 972,68 & 186,17 & 82,51 & 3,67 & 5433,32 & 612,67 & 1384,06 \\
\hline
\end{tabular}

No município de Curaçá, na composição dos RSDs, matéria orgânica apresentou 63\% (Figura 3) na composição, o que está coerente com a porcentagem média do material orgânico de origem domestica 
encontrado por Cempre, que é cerca de $60 \%$. Segundo Ministério do Meio Ambiente (MMA) os resíduos orgânicos provenientes de atividades agrossilvopastoris e industriais, os dados do Plano Nacional de Resíduos Sólidos indicam que há uma geração anual de 800 milhões de toneladas de resíduos orgânico, e correspondem a mais de $50 \%$ do total de RSU gerados no Brasil.

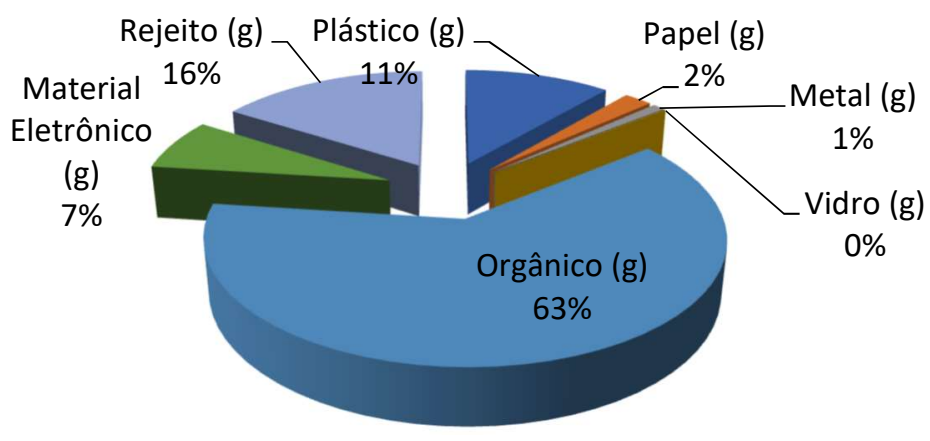

Figura 1: Percentual resíduos sólidos gerados em Curaçá

A composição dos resíduos sólidos no município permite analisar de que maneira eles se degradam e como podem contaminar o meio ambiente. Mas também, permite definir de que modo se dará o tratamento mais apropriado, além de poder recorrer a possibilidades de reutilização, reciclagem, aproveitamento energético e beneficiamento do composto orgânico.

A compostagem entra nesse contexto, como uma alternava sustentável para o município, que faz parte das Regiões Integradas em Desenvolvimento (RIDE), como principal fonte de economia a agricultura irrigável. Assim os resíduos orgânicos gerados podem ser tratados em várias escalas, desde a doméstica até uma escala industrial para produção de fertilizantes orgânicos que podem vim a ser utilizado pelos agricultores da região. Porém, segundo o IBGE, a compostagem vem decrescendo na região em $74,2 \%$, podendo ser atribuído a falta de informação sobre a técnicas e incentivos dos gestores dos próprios municípios para implantação de usinas para este determinado fim.

A figura 4 mostra o total de matéria orgânica encontrada por bairro, percebe-se uma diferença na concentração de resíduos sólidos gerados pela população que reside nos bairros de localização mais no centro da sede dos bairros quem estão situados na área periférica (Figura 4). Os José Amâncio Filho, Vila da Paz, Bambuí e Casas Populares, apresentam renda familiar mais baixa produzindo um quantitativo, quase três vezes superior ao produzido pelos bairros centrais.

O bairro José Amâncio Filho, destaca-se com o maior teor de matéria orgânica. Dessa forma, a quantidade de matéria orgânica presente nos resíduos é inversamente proporcional ao desenvolvimento e evolução das cidades, afirmando que a quantidade de resíduos orgânicos é maior em populações de renda mais baixa. O problema dos resíduos sólidos na área periférica é expressivo, já que "[...] os resíduos da produção vegetal e animal podem gerar uma quantidade de lixo muito significativa". 


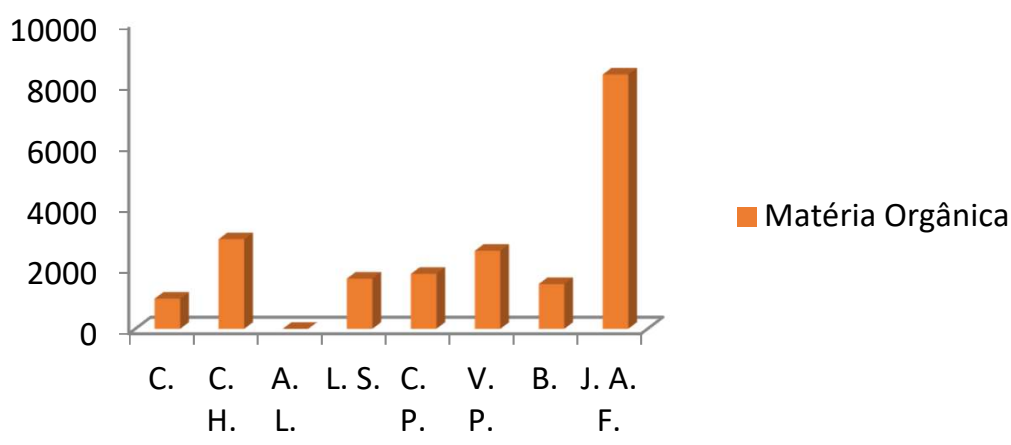

Figura 4: Total de matéria orgânica per capita (g/hab.dia) por bairro de Curaçá.

\section{Produção Total de Recicláveis e Não Recicláveis}

Segundo dados de 2008 do IBGE, divulgados por meio da Pesquisa Nacional de Saneamento Básico (PNSB), 99,96\% das cidades possuem serviços de manejo dos resíduos sólidos, no entanto $11,56 \%$ possuem triagem de reciclagem. Em Curaçá existe um espaço para a triagem de garrafas de vidro (Figura 5 e 6) que são separadas pelas famílias que sobrevivem do 'lixão', local onde retiram os materiais recicláveis que comercializam.

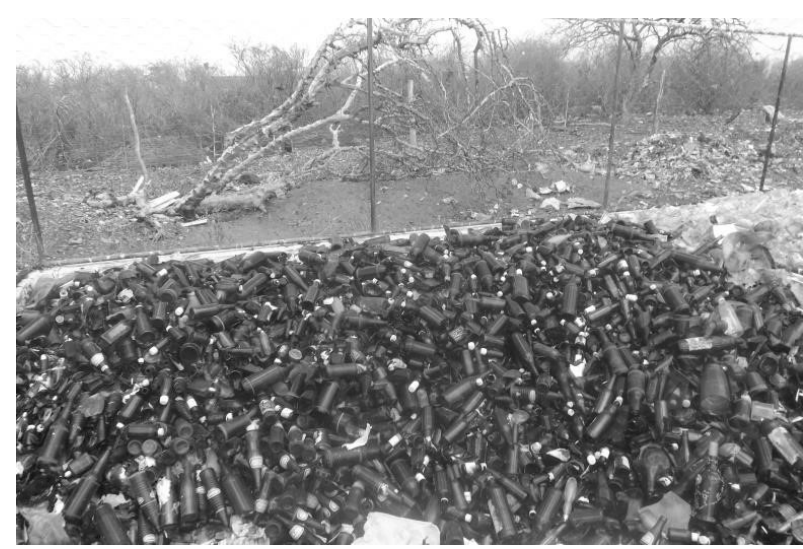

Figura 5: Garrafas de vidro alocadas na triagem

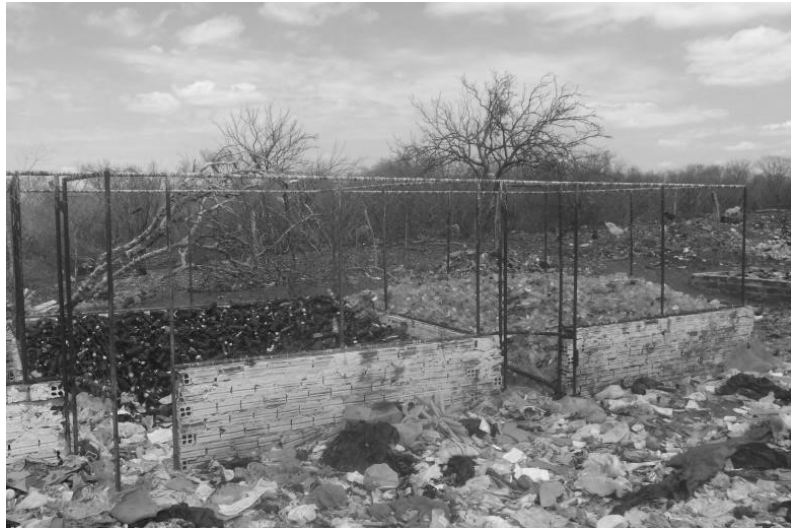

Figura 6: Espaço destinado à triagem das garrafas no lixão.

Da geração de resíduos com potencial reciclável obteve-se $29 \%$, contra $71 \%$ de material não reciclável resultante de material orgânico e rejeitos. Do total reciclável $52,36 \%$ é de material plástico e $32,98 \%$ de origem eletrônica. Esses elementos podem integrar-se, novamente, a indústria, após o seu descarte através da aplicação da logística reversa.

\section{Projeção Estimada da Geração dos Resíduos Sólidos}

A Tabela 3 traz projeções da geração de resíduos sólidos per capita da sede de Curaçá para os próximos vinte anos. É possível verificar um crescimento significativo para cada tipo de resíduos sólidos, em especial para a matéria orgânica. A necessidade da implantação de medidas que venham modificar o atual cenário da situação dos resíduos no município é imprescindível, de modo que possa atingir metas que visem reduzir, reutilizar e reciclar a quantidade de material que é encaminhado para a disposição final, sendo que tal destino deve estar ambientalmente adequado. 
Tabela 1: Projeção da geração de resíduos para os próximos 20 anos (g/hab.dia).

\begin{tabular}{|c|c|c|c|c|c|}
\hline & 2015 & 2020 & 2025 & 2030 & 2035 \\
\hline Resíduos Totais & 8675,08 & 9391,65 & 10167,42 & 11007,26 & 11916,47 \\
\hline Matéria Orgânica & 5433,32 & 5882,12 & 6367,99 & 6893,99 & 7463,45 \\
\hline Recicláveis & 1857,7 & 2011,148 & 2177,27 & 2357,117 & 2551,82 \\
\hline Metal & 82,51 & 89,33 & 96,7 & 104,69 & 113,34 \\
\hline Material Eletrônico & 612,67 & 663,28 & 718,06 & 777,38 & 841,59 \\
\hline Vidro & 3,67 & 3,97 & 4,3 & 4,66 & 5,04 \\
\hline Papel & 186,17 & 201,55 & 218,196 & 236,21 & 255,73 \\
\hline Plástico & 972,68 & 1053,02 & 1140,01 & 1234,17 & 1336,16 \\
\hline Rejeitos & 1384,06 & 1498,39 & 1622,15 & 1756,15 & 1901,21 \\
\hline
\end{tabular}

$\mathrm{Na}$ figura 7, fica nítido o alto teor de matéria orgânica que o município produz, desse modo ratificase a importância de futuramente instituir ações que objetive encaminhar o resíduo sólido orgânico para a geração de energia, visto que esse substrato possui elevado potencial energético, o qual sendo bem aproveitado pode ser utilizado para gerar energia térmica ou elétrica, bem como convertido em produto para compostagem ou fertilizante, diminuindo dessa forma, o volume de material encaminhado para a destinação final.

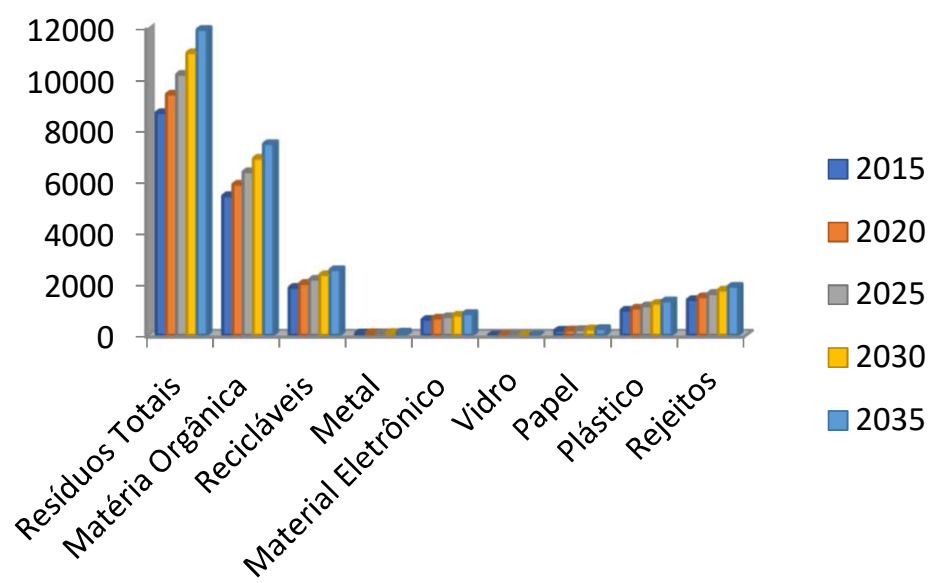

Figura 7: Projeção de cada tipo de resíduos sólidos da sede de Curaçá para os próximos 20 anos (g/hab.dia).

\section{CONCLUSÃO}

Pode-se perceber que infraestrutura local, 92\% das ruas analisadas não apresentaram lixeiras distribuídas, faltando em todas, papas entulhos destinados para coleta de construção civil. Apenas $36 \%$ havia manutenção das vias públicas. Também se constatou que, em se tratando de carros de lixo circulando para coleta dos resíduos sólidos urbanos $79 \%$ das ruas são contempladas. Existe coleta seletiva em apenas 1\% das ruas. O gestor responsável pelo serviço de limpeza urbana afirmou que todos os bairros localizados na sede de Curaçá são contemplados com o serviço de coleta de resíduos sólidos. No entanto, a destinação final dos mesmos é ineficiente, visto que é um vazadouro a céu aberto com presença de catadores e animais, não atendendo à legislação da Política Nacional de Resíduos Sólidos que entra neste cenário como um aliado, sabendo que ela estimula a formação de cooperativas de catadores, promove consórcios, educação ambiental e reúne pessoas físicas e jurídicas, de direito público ou privado e a população num dever patriótico direto relacionado aos resíduos sólidos dos que geram e daqueles que são obrigados a gerir. 
Quanto à caracterização dos resíduos sólidos da sede do município, percebe-se que $63 \%$ de todo o resíduo gerado é proveniente de matéria orgânica, sendo que $88 \%$ desse total são oriundos do bairro periférico José Amâncio Filho. Tal dado evidencia a necessidade de intervenção com medidas que fomentem a prática da compostagem e geração de energia através de processos de digestão anaeróbia para geração de biogás. Além disso, constatou-se que $71 \%$ dos resíduos gerados correspondem aos materiais que não podem ser reciclados.

\section{REFERÊNCIAS}

ADEDIPE, N. O.. Waste management, processing, and detoxification. In: CHOPRA, K.. Millennium Ecosystems Assessment. Ecosystems and Human WellBeing: Policy Responses: findings of the Responses Working Group. Washington: Island Press, 2005.

JACOBI, P. R.; BESEN, G. R.. Gestão de resíduos sólidos na Região Metropolitana de São Paulo: avanços e desafios. São Paulo em Perspectiva, São Paulo, v.20, n.2, 2006.

IBGE. Instituo Brasileiro de Geografia e Estatística. Pesquisa Nacional de Saneamento. Rio de Janeiro: IBGE, 2001.
KLUNDERT, A.. Integrated Sustainable Waste Management: the selection of appropriate technologies and the design of sustainable systems is not (only) a technical issue. Gouda: Waste, 2001.

MONTEIRO, J. H. P.; ZVEIBIL, V. Z.. Manual de Gerenciamento Integrado de Resíduos Sólidos. Rio de Janeiro: IBAM, 2001.

SNIS. Sistema Nacional de Informações sobre Saneamento. Diagnóstico do Manejo de Resíduos Sólidos Urbanos. 14 ed. Brasília: SNIS, 2017.

A CBPC - Companhia Brasileira de Produção Científica (CNPJ: 11.221.422/0001-03) detém os direitos materiais desta publicação. Os direitos referem-se à publicação do trabalho em qualquer parte do mundo, incluindo os direitos às renovações, expansões e disseminações da contribuição, bem como outros direitos subsidiários. Todos os trabalhos publicados eletronicamente poderão posteriormente ser publicados em coletâneas impressas sob coordenação da Sustenere Publishing, da Companhia Brasileira de Produção Científica e seus parceiros autorizados. Os (as) autores (as) preservam os direitos autorais, mas não têm permissão para a publicação da contribuição em outro meio, impresso ou digital, em português ou em tradução. 